\title{
Control, Conflict, Surveillance: Similarities of Themes in Dystopian Fiction and Reality Television
}

\author{
Aidan Wylie ${ }^{1}$ \\ ${ }^{1}$ Trinity College School, Port Hope, ON L1A 4K7, Canada
}

\section{ABSTRACT}

Despite substantial research into reality television and dystopian fiction, there are no studies that combine an examination of both, even though the two forms of media share a number of major themes. This research paper looks at the correlation between the shared themes of dystopian fiction and reality television. A quantitative selection process was used to determine the materials to be observed for this study, while a qualitative content analysis was used to gather data on both of the media that were being observed. The study found that each of the themes were used differently in the media, with dystopian fiction focusing on the use of control and surveillance while reality television mainly relied on conflict to entertain viewers. The data suggests that the producers of reality television play similar roles in shaping their dramas as the leaders of totalitarian governments do in the plots of dystopian fiction.

\section{Introduction}

Reality television is a genre of television that involves placing what the audience perceives to be everyday citizens in specific situations to see how they behave, normally with the incentive of winning a cash prize at the end. Over the years, such shows have ranged from cooking contests to see who is the best chef in a specific cuisine, to shows which drop seemingly ordinary people onto an island and have them participate in challenges in order to stay and potentially win a cash prize, to shows which involve a group of eligible mates trying to win the heart of a motivated suitor. The longevity of these shows suggests their popularity, such as Survivor which has run for two decades and The Amazing Race, which has run for 31 seasons.

On a seemingly different but also popular note, dystopian fiction is a specific genre of fiction that is set in a world often very much like our own, except with questionable core social values, often a corrupt government, and a storyline frequently involving the main character experiencing and fighting back against the corruption. Melissa Ames, an associate professor and Director of English Education at Eastern Illinois University, notes that "although dystopian novels have been prevalent under the young adult (YA) banner for decades, their abundance and popularity post-9/11 is noteworthy" (Ames). This is evident in such popular series as The Hunger Games, Divergent, and The Maze Runner gaining attention from fans and companies as seen in movie adaptations, to the plethora of fanfiction.

\section{Literature Review}

The popularity of these two forms of entertainment leads one to wonder how similar some of the themes found within dystopian fiction and reality television shows are. Scholars have explored this connection, looking for similarities in theme and their work has identified three key themes of control, surveillance, and conflict. 


\section{Control}

Control has been featured in many dystopian novels from the job categories in the Divergent trilogy to the hunger games in Suzanne Collins' The Hunger Games. Calvert W. Jones of the University of Maryland, College Park, and Celia Paris of the University of Toronto designed a study to see if exposure to dystopian themes in pop culture" [shaped] political relevant attitudes". Their method involved creating multiple groups of adults and older teenagers to $\mathrm{read} /$ watch dystopian content and then complete questionnaires. The main theme that they found in their experiment was the idea of government control over the population, citing many dystopian novels in which this theme appears (Jones and Paris). Additionally, Adrián Flaño Clavijo, a translator who works with the English and Spanish languages, wrote a research paper for his English studies degree comparing two famous dystopian novels, 1984 by George Orwell and Brave New World by Aldous Huxley. He concluded that while they differed in their approach, both novels featured governments attempting to turn their civilians into an unthinking uniform mass, essentially controlling the entire population as they see fit (Clavijo). This demonstrates that the plotlines of dystopian fiction appear to focus heavily on utilizing control as a center point for story progression and plot.

In terms of reality television, control is also prevalent, found in the production studio where they edit the footage of the shows in order to create an episode that they believe will retain viewers. Zizi Papacharissi (Associate Professor at the Department of Broadcasting, Telecommunications, and Mass Media at Temple University) and Andrew Mendelson (Associate Professor at the Department of Journalism at Temple University) studied why people watch reality television and "how social and psychological antecedents influence reality television viewing". They surveyed 157 university students about their reality television viewing habits/preferences and found that the main reason reality television was watched was to pass the time, with the second reason being that it offered a sense of realism compared to fictional shows. Papacharisi and Mendleson pointed out that this could be unhealthy as reality television often had scripted results, giving the viewer a false sense of reality (Papacharissi and Mendelson). This study helped demonstrate that the edits made by the producers behind the scenes enticed viewers to watch; the producers' control over the events in the shows enabled them to manipulate viewer behaviour.

After observing both sides, one can notice that dystopian fiction features control within its story, especially focusing on the idea of a corrupt government controlling a population, whereas control in reality television is through the editing of the footage, with most of the shows not featuring an obvious sign of control but having scripted events in order to cause participants to do specific reactions/tasks. While control may appear obvious to the reader of dystopian fiction, and less obvious to the viewer of reality television, it is crucial to both.

\section{Surveillance}

Surveillance has been a common theme in dystopian novels from the thought police in George Orwell's 1984, to the hidden cameras found within the glade in James Dashner's The Maze Runner trilogy. Peter Marks, an associate professor of English at the University of Sydney, wrote an article observing the role of dystopia and utopias in the field of surveillance studies, in which he analyzed three films and one novel. He found that the films and novels took a more nuanced view of surveillance than classic surveillance dystopian novels, such as 1984 (Marks). This suggests that surveillance is more of a subtler theme in dystopian fiction, with the fictional characters not being able to pinpoint where they are being watched, only that they are being watched.

Similarly, in her article about melodrama in reality television, Susan Schuyler examines the use of surveillance on a show called Undercover Boss. She notes that most participants of the shows were being kept under surveillance, normally by hidden cameras, in order to create a sense of realism. Schuyler points out that many reality television series ignore the ethical implications of surveillance, assuming that it is ok to do (Schuyler). This highlights that surveillance is often used by producers in order to capture footage for their shows, whether it is ethical or not. Although surveillance in dystopian fiction and reality television is not a common theme in current research, Schuyler and Mark's work show that it is a valid theme, worthy of consideration. 


\section{Conflict}

In dystopian fiction, conflict is often used as an obstacle for the main character to overcome. Conflict often appears in the form of competitions, like the one seen in Suzanne Collins' The Hunger Games, in which 12 boys and girls must compete in a fight to the death where there can be only one victor. Alternatively, it can be an argument between the main character and main antagonist, such as Guy Montag and Captain Beatty from Ray Bradbury's Fahrenheit 451. Douglas W. Texter, a faculty member at Eastern New Mexico University analyzed Stephen King's The Running Man. He observed some of the major plot themes of the book and theorized that it was a social commentary on police reality television shows. The main competition is the game show The Running Man, which Texter describes as "a kind of variety show" that offers aspects of police dramas and game show randomness (Texter). On a broader scale, R. E. Foust observed dystopian fiction as a logos (the principle of reason or justice) game. He noted how one can interpret dystopian fiction as resembling a chess match between opposing sides and how, by observing statements and evolution of the plot in the book, one could visualize the fight between them as a game, or conflict (Foust). Although Foust's article is limited as it doesn't explain specific examples of competitions and games in dystopian fiction, its abstract approach is important to consider, basically implying that from the perspective of the reader, the confrontation between the protagonist and antagonist resembles a conflict between good and evil.

It is clear that conflict has been a staple in reality television frequently, whether it is the main focus of an entire show like The Bachelor or actual physical and mental competition as featured in Survivor. Bryan E. Denham and Richelle N. Jones of Clemson University researched how stereotypes might influence the results of competitions on reality television programs. They analyzed three television shows (The Apprentice, Survivor, and American Idol) and categorized all of the contestants into various stereotypes. They then tracked which contestants were eliminated in what order. They found that depending on the particular show and stereotype being considered, patterns emerged. (Denham and Jones). Due to its importance in both forms of media, competition is an important consideration when observing the common themes between dystopian fiction and reality television.

\section{Conclusion}

While a review of the novels shows that similar themes are found in dystopian fiction and reality television, there is no research that has studied any relationship between the two, through the shared themes of conflict, control, and surveillance. Creators have commented on the connection themselves, with Suzanne Collins, author of The Hunger Games stating in an interview that she got the idea for her dystopian novel while flicking through television channels and observing both a reality television show and a news broadcast on the Iraq war. The similarities she saw helped inspire the idea of a competition that included survival with warlike elements being used for entertainment (Walker). This suggests potential relationships between dystopian fiction themes and reality television themes, which leads to the research question: To what extent do the common themes found within popular dystopian fiction relate to the common themes found within major reality television shows?

\section{Method}

This study of this paper used a modified mixed-method content analysis approach which was chosen as best fit for this subject area: "A content analysis is a detailed and systematic examination of the contents of a particular body of material for the purpose of identifying patterns, themes, or biases. Content analyses are typically performed on forms of human communication, including books, newspapers ... television, art, music" (Leedy 148).

The method often involves the use of multiple researchers to reduce human error. In this study, one researcher was used, as the AP student wanted to take full responsibility for data collection. There were two major parts to this method: the first part determined what materials would be analyzed, and the second part was the analysis of these 
materials, through the framework of the three themes identified in the novels, to determine any relationship between dystopian fiction and reality television.

\section{Part 1 - Selecting Materials}

Step 1: Utilizing the Google search engine to search the phrase: "best dystopian fiction of all time" with the objective of finding a varied mix of sources.

Step 2: Reviewing the list of webpages in the order they appeared, until five websites met the following criteria:

- A website had to have 20 or more items on the list (to avoid limiting the pool of potential materials)

- A website had to be a ranked list on the same topic as the search (i.e. "best", making sure to ignore subtopics such as "coolest" "cringiest")

Step 3: Adding the top 20 books on each list into a spreadsheet, eliminating duplicates. Below each book title, a score was given from 1 to 20 to each book, depending on the position the book appeared on in the list, with 1 point going to the book ranked \#1, 2 points for the book ranked \#2, etc. until all 20 books had been scored.

Step 4: In order to attempt to create a "level playing field", the researcher filled in all of the blank spaces that were created when books didn't appear on all 5 lists, by adding 21 points in each blank space. This was done to accommodate some materials which scored highly on most lists but didn't appear on all of them (to still compete with the materials that made all five lists but placed poorly in order to keep the final selection as balanced as possible).

Step 5: Once complete, steps 1-4 were repeated for reality television shows (utilizing the phrase: "best competitive reality television shows of all time" and were sorted into a separate spreadsheet.

Step 6: On each spreadsheet, the five materials that scored the fewest points were then selected for the analysis (note: the fewer the points, the higher the rank, thereby resulting in the 5 most popular titles of books and shows).

\section{Part 2 - Analyzing Selected Materials}

For analyzing the books, only the novel itself was read, and not the historical notes at the end of each book. This was done in order to observe each book on equal footing without biases, as not all books contained historical notes. For the reality television shows the first, last, and middle episodes of the latest complete season that is available online were watched (with the middle episode being found by taking the total number of episodes in the season and dividing by two). This was done in order to get a general appreciation of each show and to take notes on the show itself, with the middle episode serving as an example of a representative episode and the first and last episodes for their special roles in framing and resolving the television narrative.

For each book/episode, small notes were made every time a theme was identified in order to compare how often a particular theme appeared and how it was used:

- $\quad$ certain keywords and phrases were observed in the dystopian fiction (see Appendix A for examples).

- $\quad$ certain camera shots and phrases were observed in the reality television episodes.

The themes discovered were coded with coloured sticky notes (for books) and documented timestamps (for television) with accompanying notes (see Appendix B for examples). The notes were collected after all materials were examined and the common occurrences were observed. 


\section{Results}

\section{Dystopian Fiction}

All three themes appeared in multiple different forms over the five books analyzed during this portion of the method, with the five books selected being 1984, Fahrenheit 451, Brave New World, The Handmaid's Tale, and The Giver. (see Appendix B for chart). Below is a breakdown of each theme's usage in the dystopian fiction, as well as a chart dictating the number of times a theme was identified for each novel:

Table 1. Usage of Themes in Dystopian Fiction

\begin{tabular}{|l|c|c|c|}
\hline \multicolumn{1}{|c|}{ Title of Work } & Control & Conflict & Surveillance \\
\hline 1984 & 20 & 4 & 17 \\
\hline The Handmaid's Tale & 25 & 12 & 7 \\
\hline Brave New World & 15 & 11 & 1 \\
\hline The Giver & 12 & 1 & 2 \\
\hline Fahrenheit 451 & 6 & 7 & 7 \\
\hline
\end{tabular}

\section{Control}

Control was the most blatant theme demonstrated in all five books, as well as the most common. It was very apparent in the first half of each novel, where it was used to demonstrate the rules the leaders had placed on society in order to manipulate their movements. It was also portrayed in all of the other ways the government was using in creating their ideal world, such as Brave New World in which humans were created in a lab and genetically modified in order to create the "perfect" society. The emotional responses of the main characters to control often grounds the narrative, providing an inside look at the experiences of people living under a repressive government.

\section{Surveillance}

This theme varied in use depending on which novel was being observed. In 1984, and The Handmaid's Tale, surveillance was used by the governments as an important tool to establish and maintain control of citizens, usually by hiding spies among ordinary citizens in order to make them feel isolated and mistrustful. In all books, however, the governments enhanced their control by training citizens to look for violations of rules or other wrong behaviour.

\section{Conflict}

This was the least used theme in the majority of the books. The author usually employed it near the climax of the books by having the main character confront the main antagonist, as seen in 1984 or Fahrenheit 451, or by having the main character discover something that shakes their moral values such as The Giver or The Handmaid's Tale. Additionally, in the majority of the dystopian novels that were studied in this project, there were references to wars going on outside of the society at the focus of the narrative, expanding the sense of conflict beyond that due to the experiences of the main characters. 


\section{Conclusion}

Although all of the books considered in this study used the three identified themes, each book appeared to focus and expand on one of them more than the other two. Fahrenheit 451 focused on control over civilians by controlling knowledge and The Giver focused on control over civilians by creating a set of rules that dictated how exactly everyone was to live their lives. Both 1984 and The Handmaid's Tale focused on using the art of surveillance in order to impose fear and mistrust onto the civilians, as well as to keep a tab on everything that was going on in order to curb possible rebellions. Brave New World focused on the conflict between two very different cultures meeting and the issues that can arise out of such an encounter.

\section{Reality Television}

In the analysis of reality television shows, it was challenging to distinguish between staged and authentic reactions by participants to events. To ensure consistency, a more systematic approach was taken in which events onscreen were taken at face value, while recognizing that events were occurring behind the scenes that enabled the show to run. The five reality television shows that were selected were The Real World, Survivor, American Idol, The Bachelor, and The Amazing Race (see Appendix $\mathrm{C}$ for chart). Implementing this approach led to the following breakdown of how each theme was utilized in reality television:

\section{Control}

This theme was unused throughout most of the shows, only appearing in Survivor and The Amazing Race when one of the competitors was trying to manipulate other people through mind games and lies, as well as in the Bachelor where the Bachelor had control over who stayed in the competition and who left. However, when taking a look at how the show was made, one can notice how much control the directors have. They are able to choose who exactly appears on the show, all special challenges that take place throughout the show, which clips go into each episode, and what order they go in.

\section{Surveillance}

Like control, this theme is barely noticeable in the actual series in terms of the participants. Apart from competitors keeping an eye on one another in some of the more competitive reality shows, there are no other obvious signs of surveillance from the cast members. However, keeping in mind that someone has to be filming the show in general, we can deduce that although the show gives the appearance of just the competitors being by themselves, each person we see has at least one camera filming them. For most of the shows, it was very hard to spot a cameraperson in the actual show as they always pick clips that lack them, with the one exception of The Real World where they did not bother to hide all of the security cameras and camera people (which appeared in many shots).

\section{Conflict}

This was a major theme in all of the shows except for American Idol, which as an individual performance-based competition didn't involve a lot of interactions between the contestants. The Bachelor and The Real World were both very conflict focused as that was the main entertainment of the shows. Each show involved multiple major arguments breaking out over the course of a single episode. Survivor and The Amazing Race had less conflict being shown but still used it as an entertainment feature along with the other various twists that the directors added in each episode. 


\section{Analysis and Conclusions}

It was interesting (and unexpected) to find that the most three observed themes used in dystopian books and reality television are inversed, with control and surveillance being common in most of the novels and almost non-existent in the reality television episodes observed in this study, with conflict being the exact opposite.

The most specific preliminary conclusion is that there are similarities in the actions of the tyrannical governments in dystopian fiction and the producers of the reality television show. The three common themes considered in this paper emerge in the ways both parties behave to achieve their desired outcomes.

In the dystopian novels, the government used control to manipulate information shared with the general public in news briefings and placement of people within the community to achieve maximum productivity with minimal backlash. This is mirrored in reality television by the control the producers have in selecting clips for the final cut of the show, shaping what the audience sees and thus interprets from it. The producers also get to pick who appears in the show, meaning that they can purposefully select personalities that will complement and contradict each other in order to gain the maximum entertainment for the audience, essentially controlling the way the show will go before it has even begun.

The two parties also co-align with their usage of surveillance as well. In the dystopian novels, the government often embedded secret police within the mix of ordinary civilians to maintain control, as well as to keep tabs on what the general population was thinking of at any given time. The producers mirror this behaviour in terms of their filming crew and security. To the viewers, it appears that the contestants are alone, but in reality there are medical staff, camera people, and security around to maintain safety and create the show, acting as kind of a secret force that allows the show to run.

With respect to conflict, the two parties share common strategies. In dystopian fiction, the government encourages civilians to report one another if anything seems out of the ordinary, creating conflict when disagreements arise between individuals about what is proper behavior. In reality television, the producers usually get to choose when contestants meet each other, creating the possibility of conflict by arranging for people with contrasting opinions or personalities to meet.

The conclusions addressed in this paper add to this field by laying down groundwork that can be built upon. By knowing that the themes of control, surveillance, and conflict are used in both reality television and dystopian fiction, researchers can do more advanced studies that can use the similarities between the two forms of entertainment revealed by this study to further this research.

To address the question initially posed: while the themes of control, surveillance, and conflict are all found in both dystopian fiction and reality television, control and surveillance predominate in dystopian fiction whereas conflict is the key focus of reality television.

\section{Limitations}

A number of limitations were encountered in this research. One of the most obvious was the variation in the format of the reality television shows, with the most noticeable being the American Idol episodes, which could only be found in 2-4-minute chunks on YouTube. Additionally, sometimes it was impossible to find specific seasons or episodes of a particular show, requiring a modification of method. For example, it was impossible to obtain the most recent season of The Real World (season 23), and so season 22 was reviewed instead. A third limitation was due to the researcher being very familiar with dystopian fiction and relatively ignorant of reality television at the beginning of this study, resulting in the possibility of bias in this paper.

Additionally, some of the larger novels took more than one day to read. Because the review was spread out over several days, there is the potential that the researcher may have missed themes later in the novel, as well as experience with other forms of media outside of the study might have affected how the researcher analyzed the paper. 
Since this research was done by a solo researcher, there is also the human error involved as it is entirely possible that the researcher recorded the theme twice or not at all, as well as the possibility that the researcher could have been biased towards certain books, causing slightly skewed results.

\section{Future Research}

There is a lot of information that could be gathered on the topic of comparing reality television and dystopian fiction. Future research on comparing producers to the totalitarian governments found in dystopian fiction might also unveil some interesting results as well. A suggestion for future researchers would be to do more in-depth research on reality television as the research method used in this paper could be considerably improved. At the start of the study, a rubric could be created to observe how a specific source utilized the themes in order to gain a new understanding on the connections between dystopian fiction and reality television. Additionally, more observations could be done on the reality television portion of the method, such as observing an entire season instead of specific episodes of the season, which would allow for a better understanding of the source materials. This would allow for the researcher to understand what has happened throughout the entire season, instead of being confused when things are radically different when they skip several episodes. One interesting possibility is that reality television shows could be split up into two categories, with the drama category consisting of The Bachelor and The Real World focusing on inner and outer conflicts, and the competitive category consisting of The Amazing Race, Survivor, and American Idol focusing on challenges of brain, brawn, and skills. Each category may reflect particular strategies to maintain viewer interest, but this requires further study.

\section{References}

Ames, Melissa. "Engaging 'Apolitical' Adolescents: Analyzing the Popularity and Educational Potential of Dystopian Literature Post-9/11." The High School Journal, vol. 97, no. 1, 2013, pp. 3-20. JSTOR, www.jstor.org/stable/ 43281204.

Clavijo, Adrián Flaño. "The Depiction of Population Control in Dystopian Fiction the Case of Brave New World and 1984." Univerisdad de la Roija.

Denham, Bryan E., and Richelle N. Jones. "Survival of the Stereotypical:A Study of Personal Characteristics and Order of Elimination on Reality Television." Studies in Popular Culture, vol. 30, no. 2, 2008, pp. 79-99. JSTOR, www.jstor.org/stable/23416126.

Foust, R. E. "A Limited Perfection: Dystopia as Logos Game." Mosaic: A Journal for the Interdisciplinary Study of Literature, vol. 15, no. 3, 1982, pp. 79-88. JSTOR, www.jstor.org/stable/24777571.

Jones, Calvert, and Celia Paris. "It's the End of the World and They Know It: How Dystopian Fiction Shapes Political Attitudes." Perspectives on Politics, www.cambridge.org/core.

Leedy, Paul D., et al. Practical Research: Planning and Design. NY, Pearson, 2019.

Marks, Peter. "Imagining Surveillance: Utopian Visions and Surveillance Studies." Imagining Surveillance: Utopian Visions and Surveillance Studies. Queens Library, https://doi.org/10.24908/ss.v3i2/3.3503. 
Papacharissi, Zizi, and Andrew Mendelson. "An Exploratory Study of Reality Appeal: Uses and Gratifications of Reality TV Shows." Journal of Broadcasting \& Electronic Media.

Schuyler, Susan. "Reality Television, Melodrama, and the Great Recession." Studies in Popular Culture, vol. 37, no. 2, 2015, pp. 43-65. JSTOR, www.jstor.org/stable/43940357.

Texter, Douglas W. "'A Funny Thing Happened on the Way to the Dystopia': The Culture Industry's Neutralization of Stephen King's the Running Man." Utopian Studies, vol. 18, no. 1, 2007, pp. 43-72, www.jstor.org/stable/20719846.

Walker, Time. "Suzanne Collins' Hunger Games Trilogy Speaks to a Generation of Teenage Readers like no Other Literary Creation - but What's the Big Message?" Independent. Independent, www.independent.co.uk/arts-entertain$\mathrm{ment} /$ films/features/suzanne-collins-hunger games-trilogy-speaks-to-a-generation-of-teenage-readers-like-no-other8958113.html. Accessed 18 Nov. 2019. 